\title{
O LADO OBSCURO DAS EMPRESAS GANHADORAS DO GUIA DE SUSTENTABILIDADE DA REVISTA EXAME
}

\author{
THE DARK SIDE OF WINNING COMPANIES IN THE \\ SUSTAINABILITY GUIDE OF EXAME MAGAZINE
}

\section{Joanice Maria Araújo Diniz}

Mestra em Administração de Empresas pela Universidade de Fortaleza (Fortaleza/Brasil).

E-mail: joanicediniz@gmail.com

\section{Fábio Freitas Schiling Marquesan}

Doutor em Administração pela Universidade Federal do Rio Grande do Sul (Porto Alegre/Brasil). Professor Adjunto no Programa de Pós-Graduação em Administração da Universidade de Fortaleza (Fortaleza/Brasil).

E-mail: marquesan@unifor.br

\section{Abílio Peixoto Diógenes}

Mestre em Administração de Empresas pela Universidade de Fortaleza (Fortaleza/Brasil). Professor na Universidade Estadual Vale do Acaraú (Sobral/Brasil).

E-mail: abiliodiogenesjr@gmail.com

\section{Rafael Fernandes de Mesquita}

Doutor em Administração pela Universidade Potiguar (Natal/Brasil).

Professor do Instituto Federal do Piauí (Piripiri/Brasil).

E-mail: rafael.fernandes@ifpi.edu.br 


\section{RESUMO}

Há um consenso acerca da ideia de que as empresas devem se conscientizar no que diz respeito às práticas de sustentabilidade organizacional e responsabilidade socioambiental. Um consenso que aceita, por meio da adoção de ações tidas como modelos de atuação responsável, que empresas recebam premiações e sirvam de benchmarking para outras. Ser "sustentável", neste contexto, poderia implicar, também, estar em evidência, por ser algo condizente à visão acerca de como a ação empresarial pode ser responsável quanto às práticas socioambientais. Nesse sentido, esta pesquisa, caracterizada como qualitativa de análise documental, objetiva analisar três casos de empresas listadas em um ranking de sustentabilidade de um veículo de comunicação que se autodenomina a maior revista de economia do país, a partir do contraponto ligado à identificação de aspectos inadequados ao conceito. Os resultados apontam que os feitos tidos como sustentáveis são desenvolvidos em paralelo a outras atividades que podem ser caracterizadas como injustas e/ou prejudiciais ao meio ambiente. No entanto, isto não implica dizer que estas empresas são as únicas a fazer isso ou que são as vilãs do mercado, mas que também se torna necessário apontar uma visão que questiona as ações empresariais por trás de práticas tidas como sustentáveis, uma análise que se posicione como essencialmente crítica e busque alternativas às práticas organizacionais vigentes.

Palavras-chave: Sustentabilidade. Estudos Socioambientais. Revista Exame. Pop Management.

\section{ABSTRACT}

There is a consensus on the idea that companies should be aware of the practices of organizational sustainability and socio-environmental responsibility. A consensus that accepts, through the adoption of actions considered as models of responsible performance, that companies receive awards and serve as benchmarking for others. Being "sustainable", in this context, could also imply being in evidence, for being something consistent with the vision about how business action can be responsible regarding socioenvironmental practices. In this sense, this research, characterized as a qualitative document analysis, aims to analyze three cases of companies listed in a sustainability ranking of a communication vehicle that calls itself the largest economy magazine in the country, from the counterpoint linked to the identification of aspects inappropriate to the concept. The results show that the achievements considered sustainable are developed in parallel to other activities that can be characterized as unfair and/or harmful to the environment. However, this does not imply that these companies are the only ones to do this or that they are the villains of the market, but that it is also necessary to point out a vision that questions the business actions behind practices considered to be sustainable, an analysis that position it as essentially critical and seek alternatives to current organizational practices.

Keywords: Sustainability. Socio-environmental Studies. Exame Magazine. Pop Management. 


\section{INTRODUÇÃO}

As discussões que vêm sendo travadas sobre a questão da sustentabilidade foram aprofundadas nos últimos anos e, embora a ideia angarie aceitação global quase que unânime, uma gama de estudiosos ainda contesta a extensão do conceito e busca contextualizações mais objetivas para evitar interpretações errôneas (MAZLOOMI; HASSAN, 2008). Já que interpretação desse conceito é considerada inconsistente e um tanto ambígua, decorre-se uma incompreensão dos problemas relacionados à pobreza, à degradação ambiental e aos efeitos do crescimento econômico a qualquer custo (MORI; CHRISTODOULOU, 2012; SLIMANE, 2012), fragmentando a noção de sustentabilidade e deixando à margem alguns problemas que poderiam também ser compreendidos na interpretação de sua abrangência.

A sustentabilidade, em suas concepções mais mainstream, por assim dizer, é condizente com uma ideia de crescimento econômico baseado na justiça social e na maior eficiência no uso de recursos naturais (LOZANO, 2012). Por outro lado, a perspectiva crítica adotada neste trabalho exige o rompimento com a mentalidade macroeconômica vigente, a compreensão dos limites naturais em relação às atividades econômicas e o fim da lógica social ancorada no aumento e na dependência do consumo (VEIGA, 2010).

É fato inconteste que as empresas devem se conscientizar no que diz respeito às práticas de sustentabilidade organizacional e responsabilidade socioambiental (MESQUITA et al., 2020). Tratase da configuração de um consenso que aceita, por meio da adoção de ações tidas como modelos de atuação responsável, que as empresas recebam premiações e sirvam de benchmarking para outras. Ser "sustentável", nesse contexto, pode implicar, também, estar em evidência, por ser algo condizente à visão acerca de como a ação empresarial pode ser responsável quanto às práticas socioambientais. Nesse quadro, conforme afirma Banerjee (2003, p. 81), a sustentabilidade não passa de um slogan: "Ela é um slogan e slogans, embora bonitos, não fazem teoria".

Mas a visão que enaltece esse aspecto, do destaque às práticas sustentáveis, pode ser míope quando se refere ao potencial lado obscuro das práticas organizacionais de modo geral. O lado obscuro passa a ser uma sombra, uma possivel contradição do que está em evidência e o que é desenvolvido em práticas corriqueiras e negligenciadas, como envolvimento de corporações em práticas moralmente inaceitáveis, violações civis e administrativas (MEDEIROS et al., 2018).

Dentro de uma perspectiva de administração "domesticada" (MISOCZKY; AMANTINO-DE-ANDRADE, 2005), é comum se ter organizações promovendo sustentabilidade por meio de ações pontuais, superficiais ou compensatórias, sem o devido envolvimento da sociedade, mas com efeitos deletérios sobre ela. E estas práticas pontuais são as principais ações propagadas em larga escala pela imprensa, externando ao público uma visão parcial e unilateral das práticas organizacionais vigentes. Mas, se desenvolvida numa 
perspectiva radical, isto é, de se ir às raízes (MARX, 2005), constata-se, facilmente, que há outro lado a ser observado e, por vezes, esse lado é perverso, obscuro, além de ignorado pelo mainstream da ciência da administração (FOTAKI; PRASAD, 2015).

Para Ituassu e Tonelli (2014, p. 86), "a lógica das modernas práticas de gestão ultrapassou a esfera econômica e disseminou-se como modelo de conduta para outras esferas da vida social, em um processo denominado, management ou cultura do management". Assim, "esse processo trouxe, entre outros valores, modelos de sucesso que se propagaram a partir da mídia de negócios. A mídia, entendida como comunicação de massa, possibilita a mercantilização e a circulação de formas simbólicas" (ITUASSU; TONELLI, 2014, p. 86). O chamado management industry, pop management ou cultura do management é caracterizado pela "reprodução de determinados padrões conceituais concebidos como de natureza acrítica, volátil e superficial sobre os fenômenos administrativos" (MOURA, 2014, p. 64).

Por conseguinte, ao tratar de sustentabilidade, revistas de negócios podem privilegiar uma visão que não corresponde ao estado da arte de discussões acadêmicas, ou que não corresponda ao que seria observado em uma análise mais crítica dos fenômenos retratados. Deste modo, percebe-se que há uma lacuna na análise das publicações de pop management, do ponto de vista crítico em relação à sustentabilidade, que justifica o desenvolvimento de estudos teóricos nesta linha.

Nesse sentido, este trabalho objetiva analisar três casos de empresas listadas em um ranking de sustentabilidade (Guia Exame de Sustentabilidade) em uma revista que se autodenomina a maior revista de economia do país (EXAME, 2016; BARROS; SAUERBRONN; COSTA, 2014), a partir do contraponto à identificação de aspectos inadequados ao conceito. As informações de contraste, sobre injustiças e danos ambientais indicados como causados pelas empresas listadas foram encontradas no site "Mapa de conflitos envolvendo injustiças ambientais e saúde no Brasil" (CONFLITO AMBIENTAL, 2016). O site Mapa de conflitos é um projeto desenvolvido pela Fiocruz (Fundação Oswaldo Cruz) e pela Fase (Federação de Órgãos para Assistência Social e Educacional) com apoio do Ministério da Saúde do Brasil.

\section{UMA CRÍTICA À SUSTENTABILIDADE E À PRODUÇÃO (NEO)EXTRATIVISTA}

A ideia de metabolismo social (MARX, 2005) salienta que o homem transforma a natureza a partir de uma mediação feita pelo trabalho, sendo que, nesse movimento, ele também se transforma. "O trabalho é, então, um processo entre homem e natureza. Ao mesmo tempo em que o homem se diferencia da natureza pelo trabalho, torna-se alienado diante do trabalho e em relação à natureza" (FREITAS; NÉLSIS; NUNES, 2012, p. 43). 
Na analogia de um organismo vivo, pensadores como Marx e Engels estavam diante da relação predatória praticada por organizações a fim de explorarem o máximo de recursos naturais em busca de lucro e da acumulação de riquezas (FREITAS; NÉLSIS; NUNES, 2012). Esta análise já identificava o perfil de organizações que lucram em cima da destruição e da fragilização de comunidades periféricas, mesmo antes da prática que se tem, hoje em voga, caracterizada como a "sustentabilidade".

A definição de "sustentabilidade" pode ser considerada ainda vaga e superficial, apesar, ou talvez pelo próprio motivo, de ser amplamente utilizada, seja na academia, seja nos discursos políticos e das corporações. Nos chamados Estudos Organizacionais (EOs), uma profusão de termos e definições aumenta ainda mais o conflito entre os conceitos, principalmente sobre ecologia e sustentabilidade (SHRIVASTAVA, 1994). Shrivastava e Berger (2010) também endossam a superficialidade dos conceitos de sustentabilidade, que, para eles, é formada por uma gama de princípios cuja eficácia prática é incerta devido à complexidade das organizações. O que é vago no conceito está relacionado ao uso que se faz da sustentabilidade, que superficial, acaba utilizado como verniz para a divulgação de atividades que não são sustentáveis nem responsáveis (SICA; BIANQUINI; TERRERI, 2019). Assim, encontram-se abordagens relativas à sustentabilidade organizacional em profusão em detrimento da sustentabilidade forte, ecocêntrica e efetiva (MILNE; KEARINS; WALTON, 2006).

Robinson (2004) ressalta que é preciso avançar no conceito e entendimento de sustentabilidade e responsabilidade iniciado na década de 1960, admitindo uma prática integradora dos diversos setores e representações e adotando uma visão coletivista. Caso contrário, um risco é que a sustentabilidade em empresas se torne apenas uma fachada conveniente, tendo pouco significado substancial (ABSON et al., 2017; DE LANGE; BUSCH; DELGADO-CEBALLOS, 2012).

Deste modo, a sustentabilidade começa a ser questionada por ser considerada controversa e oportuna, mascarando a incompatibilidade entre crescimento econômico e exploração de recursos naturais (REDCLIFT, 2009). Banerjee (2011) emerge nessa conjuntura questionando se empresas devem focar um pouco menos no crescimento ilimitado e ter responsabilidade de abordar problemas relacionados à desigualdade de renda, assistência médica e educação de seus stakeholders.

Sob tais circunstâncias, corrobora-se a observação de Banerjee (2011), de que é necessário olhar para questões, definições, práticas organizacionais e políticas públicas sobre sustentabilidade e responsabilidade social utilizando uma análise crítica com ações reais globais e não apenas intencionais, pontuais, obscuras, conflitantes e, inadequadamente, transferidas para os stakeholders. Assim, deve-se atentar para práticas ditas sustentáveis que mascaram injustiças socioambientais e ainda prejudicam e procrastinam a implantação de ações sustentáveis fortes, democráticas, denunciadoras e calcadas na justiça. 
Torna-se quase um imperativo, no mercado corporativo atual, que as empresas invistam em sustentabilidade. Este ditame é o que pode motivar líderes a participar de premiações e certificações na área de negócios. Desse modo, companhias tentam alcançar a sustentabilidade por meio de estratégias de competitividade que promovem incrementos gerenciais ambientais, a exemplo das tão difundidas "tecnologias limpas" (SHRIVASTAVA, 1995). Como as empresas selecionadas para este estudo têm produção extrativista, ou apoiam e investem neste tipo de produção em sua cadeia, cabe aqui a inclusão de um entendimento teórico crítico acerca do extrativismo.

O novo extrativismo acentua um processo de "desterritorialização" no qual o Estado não consegue assegurar sua presença de forma adequada e homogênea em todo seu território e é, ao mesmo tempo, ativo na promoção e defesa de enclaves mineradores ou petroleiros (VERDUM, 2009). Gudynas (2009) destaca uma ampliação de práticas extrativistas tradicionais latino-americanas, como monocultura em grande escala e produção voltada para exportação. Este extrativismo se apoia ora sobre a égide do petróleo e seus derivados, ora pelos mesmos produtos e práticas ditas convencionais; em ambos, mantém poder degenerador. Assim, mesmo governos progressistas seguiam apostando nestas exportações e, portanto, se esforçavam para buscar uma inserção, ainda que periférica, nos mercados globais (GUDYNAS, 2012).

Isso implica aceitar a institucionalidade da globalização, ajustar-se às regras comerciais da Organização Mundial do Comércio (OMC) e incentivar a liberalização do fluxo de capitais. Reforça-se, dessa maneira, um papel subordinado das nações periféricas nos mercados globais, em que as nações sulamericanas são tomadoras de crédito, dependem dos intermediários e dos fluxos de capital, configurando o neo-extrativismo como inerente à globalização contemporânea (VERDUM, 2009).

Qualquer atividade agrícola que emprega recursos naturais, como água e solo, e usa insumos como fertilizantes e praguicidas, provoca algum impacto ambiental, seja através da redução da biodiversidade, da contaminação das águas superficiais e subterrâneas e do solo, da compactação do solo, do assoreamento de corpos d'água e dos danos à flora e à fauna. Deste modo, atividades humanas chamadas econômicas alteram o meio ambiente, sendo a mineração e a agricultura as duas atividades econômicas básicas da economia mundial, sendo a primeira uma das que mais tem impacto. Através destas, o homem extrai recursos naturais que alimentam toda a economia. E sem elas, nenhuma das atividades subsequentes pode existir (SILVA, 2007).

A mineração, a agricultura e a exploração florestal, focos deste artigo, juntamente com a produção de energia, os transportes, a construção civil e as indústrias básicas (químicas e metalúrgicas) são causadores de grande parte dos danos ambientais existentes na Terra. O impacto das demais atividades econômicas se torna pouco significativo quando comparado às citadas anteriormente (SILVA, 2007). Algumas destas empresas, inclusive, estão envolvidas em desastres ambientais que acarretam em 
prejuízos e deslocamento ambiental de grande número de pessoas, principalmente os mais vulneráveis (JUNG, 2017).

A fim de minimizar a imagem degradante, empresas extrativistas passam, então, a adotar um perfil ligado à sustentabilidade como uma maquiagem pública para suas atividades ambientalmente danosas. Com grande relevância econômica nos mercados nacional e internacional, as grandes companhias recebem apoio de vários setores também interessados em compartilhar dos benefícios econômicos. Muitas delas, no entanto, negligenciam, principalmente, a dimensão social da sustentabilidade e a atuação interna perante os colaboradores (SICA; BIANQUINI, TERRERI, 2019).

Assim, publicações como a revista e o ranking que ela divulga enaltecem estas ações empresariais. Deste modo, faz-se importante compreender os impactos causados pelas atividades econômicas para que haja melhor entendimento das próprias formas de exploração empregadas por essas firmas.

\section{MÉTODO DE TRABALHO}

Esta pesquisa se caracteriza como qualitativa de análise documental (MESQUITA; MATOS, 2014). Os documentos analisados foram obtidos na "Revista Exame" e via web nos sites da "Exame" e do "Mapa de Conflitos Ambientais". O critério de escolha das três empresas foi definido pela visibilidade das firmas listadas entre as cinco primeiras classificadas. Assim, decidiu-se que as companhias Elektro e Algar Telecom, as duas primeiras colocadas pela pontuação de 2015, não seriam analisadas neste trabalho, pois a Elektro, concessionária de Energia, e a Algar, operadora de telefonia, têm porte inferior em relação às outras colocadas, tanto em faturamento quanto em número de funcionários.

A seguir, nas linhas que seguem, será feita uma breve apresentação da revista, do Guia e do Mapa de conflitos.

\subsection{A REVISTA EXAME}

A revista Exame se define como a maior e mais influente publicação de negócios e economia do país (EXAME, 2016a). Publicado quinzenalmente, o periódico pretende levar à comunidade de negócios informações e análises conjunturais sobre temas como estratégia, finanças, marketing, gestão, consumo, sustentabilidade, recursos humanos e tecnologia (EXAME, 2016a). A marca Exame também está presente em outras plataformas, como aplicativos e redes sociais. A página Exame.com no Facebook tem cerca de três milhões e meio de seguidores (EXAME, 2016b). A Editora Abril, responsável pela revista, é o maior grupo editorial do país, envolvida na publicação de mais de trezentos títulos, além de participar das indústrias de livros didáticos, TV a cabo e marketing. Sete das dez revistas mais lidas do país são 
desta editora. A sua edição de maior sucesso, a Veja, é a revista semanal mais vendida no mundo fora dos Estados Unidos (BARROS; SAUERBRONN; COSTA, 2014).

Como público principal, a Exame define seu enunciatário como "empresários, executivos, autoridades e profissionais de destaque que decidem os rumos da economia no Brasil" (EXAME, 2016b). Segundo o instituto de pesquisa Ipsos-Marplan, a revista é lida por cerca de $90 \%$ de presidentes das quinhentas maiores empresas do país e ainda tem entre leitores vice-presidentes, diretores e empresários do Brasil, o que demonstra a importância do periódico neste segmento. O perfil do leitor da revista é composto por homens (54\%), entre trinta e quarenta e nove anos (44\%) e da classe AB $(85 \%)$. Seus anúncios publicitários podem variar entre valores de $R \$ 20$ mil na versão eletrônica e $R \$ 495$ mil na revista impressa (EXAME, 2016b).

\subsection{O GUIA E A PESQUISA QUE EMPREENDEMOS}

Em relação ao método empregado na classificação, das duzentas e dez empresas participantes da seleção do Guia em 2015, sessenta e oito empresas-modelo foram apresentadas por vinte e um setores, com destaque especial para as companhias com as melhores práticas em cada um deles. Para entender o desempenho das empresas, a revista criou notas aplicadas nos questionários elaborados pelo Centro de Estudos da Fundação Getúlio Vargas (GVces), pontuando as dimensões econômica, social, ambiental e geral. O GVces é considerado referência em estratégias, políticas e ferramentas de gestão em sustentabilidade no país (EXAME, 2015).

A Exame também selecionou o maior destaque de todo o ano, ou seja, a companhia que recebeu o prêmio de 'Empresa Sustentável do Ano' com base nas pontuações e em critérios jornalísticos. Sobre o 'Guia Exame de Sustentabilidade', as organizações que aspiram entrar na lista devem se inscrever e responder a uma série de questões elaboradas pelo Centro de Estudos da Fundação Getúlio Vargas (GVces) e disponíveis no site da revista (EXAME, 2016b).

A etapa inicial seleciona as empresas de acordo com o questionário, que compreende um levantamento sobre o desempenho das empresas sob os aspectos econômico-financeiros, sociais e ambientais. Em outra etapa, um grupo formado por especialistas indicados pela revista analisa as empresas e seleciona as que merecem destaque. Além disso, a revista destacou as companhias com as melhores práticas em dez categorias: Governança de sustentabilidade; Direitos humanos; Mudanças climáticas; Relação com a comunidade; Relação com clientes; Gestão de fornecedores; Gestão de água; Gestão de biodiversidade; Gestão de resíduos; e Ética e transparência. 
Deste modo, obteve-se um total de setenta e oito empresas destacadas no ranking de sustentabilidade de 2015. As empresas foram classificadas com base na melhor pontuação, na avaliação do conselho deliberativo do guia e em "critérios jornalísticos" - que, infelizmente, não são especificados.

Participaram do Conselho do "Guia Exame de Sustentabilidade de 2015" o coordenador do Grupo de Estudos de Governança e de Ética do Instituto Brasileiro de Governança Corporativa; a coordenadora do Centro de Empreendedorismo Social e Administração em Terceiro Setor da USP; o gerente do IFC no Brasil; um especialista socioambiental do IFC; a diretora-presidente do Centro Ruth Cardoso e da ONG Comunitas; o diretor-executivo do Uniethos e o coordenador do Sistema de Estimativa de Emissão de Gases de Efeito Estufa, do Observatório do Clima.

Para a verificação dos danos ambientais causados pelas empresas (Tabela 1), isto é, para a elaboração do contraponto às informações prestadas pela Exame, foi utilizado o site "Mapa de conflitos envolvendo injustiças ambiental e saúde no Brasil" (CONFLITO AMBIENTAL, 2016). O "Mapa de Conflitos" é resultado de um projeto desenvolvido em conjunto pela Fiocruz com o apoio do Departamento de Saúde Ambiental e Saúde do Trabalhador do Ministério da Saúde. O Mapa de Conflitos tem objetivo de apoiar a luta de inúmeras populações e grupos atingidos em seus territórios por projetos e políticas baseadas numa visão de desenvolvimento considerada insustentável e prejudicial à saúde (CONFLITO AMBIENTAL, 2016). 
Tabela 1 - Indicação de danos registrados

\begin{tabular}{|c|c|c|c|}
\hline Indicação de danos registrados & Itaú & Fibria & Bunge \\
\hline Acidentes & 2 & 1 & 2 \\
\hline Acidentes de trabalho & & & 1 \\
\hline Doenças transmissíveis ou crônicas & & 2 & 4 \\
\hline Doenças transmissíveis & 2 & 1 & \\
\hline Desmatamento & & & 1 \\
\hline Contaminação dos rios & & & 2 \\
\hline Falta de atendimento médico & 1 & 1 & 1 \\
\hline Piora na qualidade de vida & 2 & 4 & 3 \\
\hline Violência - ameaça & 2 & 2 & 2 \\
\hline Violência - coação física & 2 & 2 & 1 \\
\hline Insegurança alimentar & 1 & & \\
\hline Doença de Chagas & 1 & & \\
\hline Uso de agrotóxico e transgênico & & & 2 \\
\hline Uso de agrotóxico e contaminação & & 1 & \\
\hline Morte & & & 1 \\
\hline \multirow[t]{2}{*}{ Suicídio } & & & 1 \\
\hline & TOTAL & 14 & 21 \\
\hline
\end{tabular}

Fonte: Adaptado de (CONFLITO AMBIENTAL, 2016)

As fontes obtidas pelo site provêm, em grande parte, da Rede Brasileira de Justiça Ambiental (RBJA). Os dados do "Mapa de Conflitos" também são complementados pelo acesso a informações da mídia ou de instituições, incluindo órgãos como Ministério Público. 


\section{RESULTADOS - ANÁLISE DE INFORMAÇÕES DAS EMPRESAS PREMIADAS}

Nesta seção são discutidos os resultados encontrados durante o trabalho de pesquisa.

\subsection{BUNGE}

A Bunge é apontada como a terceira maior exportadora do Brasil e a maior exportadora do agronegócio. É ainda considerada a maior processadora de grãos como soja, milho e caroço de algodão do país. Em 2012, a área de Agronegócio e Logística da empresa comercializou, nos mercados interno e externo, mais de vinte milhões de toneladas de grãos, relacionando-se com dezessete mil agricultores, além de cooperativas agrícolas, por todo o Brasil (BUNGE, 2020).

A empresa, criada na Holanda, explica que em mais de cem anos no mercado nacional participou ativamente para concretizar a vocação brasileira de grande produtora de alimentos (BUNGE, 2020). A sustentabilidade encontra-se entre as missões da empresa, que consiste em "melhorar a vida, contribuindo para o aumento sustentável da oferta de alimentos e bioenergia, aprimorando a cadeia global de alimentos e do agronegócio" (BUNGE, 2020).

A Bunge está presente no Guia de Sustentabilidade desde 2009. Com faturamento de $\mathrm{R} \$ 40,1$ bilhões em 2014 e mais de dezesseis mil funcionários, a companhia tem cerca de vinte mil fornecedores em dezessete estados. Por conta da escala, da proporção do negócio, além da postura "sustentável" da companhia, a Exame a indicou a Bunge como 'A Empresa Sustentável do Ano' (EXAME, 2015). A reportagem "Poupando a Água Sem Reduzir a Produção" classifica como principal proeza da Bunge conseguir o mérito de adotar uma prática sustentável, sem, no entanto, reduzir lucros.

A própria revista indica que a empresa apenas passou a banir o plantio de soja na floresta Amazônica após a divulgação de um relatório da ONG Greenpeace, intitulado "Comendo a Amazônia", que motivou a criação da "moratória da soja", pacto assinado por empresas deste setor com o objetivo de banir a soja da cadeia produtiva da Amazônia. Ainda na reportagem, o secretário-geral da Associação Brasileira das Indústrias de Óleos Vegetais (Abiove) afirma que o mercado europeu exige fornecimento calcado no respeito ao Código Florestal Brasileiro. Esse "respeito" a uma legislação nacional é tratado como iniciativa sustentável louvável à premiação. Por conta do mercado internacional, a Bunge assumiu o compromisso de eliminar o desflorestamento em 2015.

\subsubsection{Indicação de danos}

No Guia Exame não são mencionados os problemas ambientais pelos quais a empresa é responsável. Entre os danos apontados no site Conflitos Ambientais estão devastação ambiental, poluição e contaminação. O Mapa de Conflitos registrou vinte e uma ocorrências envolvendo a companhia em 
sete estados brasileiros. Na região nordeste foi registrada degradação e ameaça ambiental da saúde e do trabalho no Maranhão por conta do avanço da monocultura da soja. No Piauí, indica-se que uma área de transição da caatinga, cerrado e floresta foram impactadas pela companhia, que além da monocultura, usa carvão vegetal para o processamento desses grãos.

No sul do país, Santa Catarina registrou insegurança e contaminação dos recursos hídricos e do solo por conta da mineração de fosfato ao longo do rio Braço do Norte. Já em Passo Fundo, Rio Grande do Sul, a empresa é apontada por monopólio da indústria alimentícia e por favorecimento do Estado, além da prática de atividades que alteram o regime tradicional de uso e ocupação de território. Em São Paulo, uma cooperativa ligada à empresa opera em terreno contaminado, o que acarreta em transmissão de doenças devido à poluição do solo.

Na região centro-oeste, funcionários da indústria de alimentos do Mato Grosso do Sul registraram queixas relativas à insegurança do trabalho. No Tocantins, a instalação de monocultura de soja, além de agredir o território amazônico, aumentou a pobreza e a desigualdade social atingindo povos indígenas e ribeirinhos.

A prática extrativista de monocultura adotada pela Bunge condiz com as questões levantadas por Silva (2007) em relação ao grande impacto ambiental, bem mais significativo que o praticado pelas demais atividades econômicas. O impacto social, como questões de segurança dos trabalhadores e aumento da desigualdade entre os atingidos costumam ser negligenciados pelas companhias brasileiras (SICA; BIANQUINI, TERRERI, 2019). Mas essa postura deve ser combatida e a sustentabilidade no âmbito social, por meio de resolução de conflitos e harmonização da comunidade local, deve ser assumida (LARA; OLIVEIRA, 2017).

\subsection{FIBRIA}

Formada a partir da fusão de Aracruz e Votorantim Celulose e Papel, consolidada e oficializada em 2009, a empresa é a maior produtora de celulose de eucalipto do Brasil e possui capacidade produtiva de mais de cinco milhões de toneladas anuais de celulose. Em sociedade com a Cenibra, opera o único porto brasileiro especializado em embarque de celulose, Portocel - Terminal Portuário de Barra do Riacho (Aracruz, ES), considerado o terminal mais eficiente do setor no mundo. A marca Fibria foi descontinuada em 2019, após fundir-se com a Suzano Papel e Celulose.

A Fibria aponta o aumento do consumo do produto como um indicador de desenvolvimento socioeconômico. O discurso, em princípio contraditório com as amplas ações que propõem redução do uso e reutilização do papel, evidencia a estreita relação que a empresa procura estabelecer entre a sustentabilidade e a manutenção do próprio negócio. A empresa frisa que procura atender a emergente 
demanda global por papel de forma sustentável (FIBRIA, 2016). Ao desvincular a redução do consumo da ideia de sustentabilidade, a Fibria define-se como sustentável porque busca contribuir para uma sociedade sustentável, fornecendo com eficiência econômica e responsabilidade social e ambiental a matériaprima preferida para a fabricação de tipos muito usados de papel: a celulose de eucalipto (HENRIQUES; SANT'ANA, 2013).

A reportagem 'A Floresta Nativa Ajuda a Aumentar a Produtividade' da 'Exame' classificou a Fibria em quinta colocação no ranking geral de desempenho do Guia de Sustentabilidade e concedeu o título de empresa mais sustentável do setor de papel e celulose. Em 2014, a Fibria foi eleita a mais sustentável do ano pelo mesmo Guia. Participante do Guia desde 2009, a empresa mantém quatro mil e trezentos funcionários e faturamento de R\$ 7,3 bilhões em 2014 (EXAME, 2015).

Uma das proezas apontadas pela 'Exame' é a análise da qualidade de resistência do eucalipto. 0 presidente da Fibria disse na reportagem que a adaptabilidade à mudança climática está no centro da estratégia empresarial. A empresa costuma mensurar resultados pelo retorno dos investimentos em sustentabilidade. Também se apontou a manutenção da mata nativa ao lado das plantações como fator benéfico para produtividade, mesmo com maior custo do cultivo de mata nativa. Para o presidente da Fibria, trata-se de um investimento de "ganha-ganha" (EXAME, 2015).

\subsubsection{Indicação de danos}

Com catorze danos ambientais registrados pelo Mapa de Conflitos, os estados apontados como mais afetados pela companhia são Espírito Santo e Bahia (CONFLITO AMBIENTAL, 2016). No sul da Bahia, no município de Eunápolis, a empresa foi acusada de adquirir irregularmente terras de território Tupiniquim e Guarani e de comunidades quilombolas. Em 2008, a empresa Jurong do Brasil e o Governo do Estado do Espírito Santo firmaram acordo para a implantação de um estaleiro no município de Aracruz. O local fica próximo ao porto abrigado de Barra do Riacho, onde se localiza o terminal Portocel, da Fibria. As atividades do estaleiro reforçam os danos socioambientais que atingem populações indígenas e tradicionais das localidades.

As acusações contra a Fibria no "Mapa de Conflitos" vão desde o desmatamento da Mata Atlântica para a plantação do eucalipto ao desrespeito às leis trabalhistas, passando por irregularidades na aquisição de terras, invasão de terras indígenas e influência no aumento do êxodo rural. Ainda foram registrados problemas como doenças transmissíveis, falta de atendimento médico, piora na qualidade de vida, violência por ameaça, coação física ou lesão corporal, além de insegurança alimentar e contaminação por agrotóxicos. 


\subsection{ITAÚ}

Em 2014, a marca foi apontada como a mais valiosa no Brasil pelo décimo primeiro ano consecutivo, com um valor estimado de $\mathrm{R} \$ 21,7$ bilhões (EXAME, 2015). Considerado o maior banco da América do Sul e do hemisfério sul no setor de varejo e múltiplo, o Itaú oferece serviços de finanças e seguros a milhões de clientes. Esse posto foi conquistado após novembro de 2008, ao anunciar a fusão com o Unibanco.

Na revista Exame, Itaú Unibanco, além da quarta colocação geral, também foi a mais sustentável do setor "Instituições Financeiras". Presente em dez edições do Guia, o Itaú faturou em 2014 mais de R\$157 bilhões. Na matéria 'Ensinando a Poupar Para o Amanhã' (EXAME, 2015), a instituição recebe destaque em relação a investimentos na educação financeira e organização de finanças pessoais, que resultaram num aumento na parcela de clientes com investimentos em previdência privada e fundos de investimentos, trazendo bons resultados para o banco. Voluntários também participaram de campanhas de educação financeira, inclusive em escolas.

Outro projeto mencionado, voltado ao incentivo da literatura infantil, distribuiu quarenta e cinco milhões de livros desde 2006 e foi destaque como uma das causas sociais do banco que, segundo o presidente Roberto Setúbal, ajudam na cidadania. "Cidadãos conscientes podem ter uma sociedade melhor" (EXAME, 2015, p. 156).

Não foram mencionadas na revista políticas com componentes socioambientais específicos aplicadas às linhas de negócios ou processos para aperfeiçoar a competência dos colaboradores em implementar procedimentos socioambientais, como constata-se em (ALMEIDA et al., 2017).

\subsubsection{Indicação de danos}

O "Mapa de Conflitos" (CONFLITO AMBIENTAL, 2016) aponta possível envolvimento da instituição financeira no financiamento de obras irregulares. Foram detectadas treze ações danosas relacionadas ao banco, como a fragilidade no processo de licenciamento ambiental do Complexo Portuário de Açu, que coloca em risco comunidades de trinta e dois municípios dos estados de Minas Gerais e Rio de Janeiro.

Este conflito surgiu em decorrência do projeto de instalação da mina Apolo pela mineradora Vale, em Minas Gerais, numa área de Mata Atlântica. Cerca de R\$ 2 bilhões em dívidas estavam perto do vencimento, especialmente aquelas contraídas por bancos como Itaú, Caixa, BNDES e ARAB Banking Corporation. A população atingida está exposta a riscos de alteração no regime tradicional de uso e ocupação do território, desmatamento e irregularidade de licenciamento ambiental.

O Itaú, junto com outros bancos brasileiros, também é apontado como envolvido no financiamento de empreendimentos imobiliários em Salvador (BA), onde comunidades de encostas e favelas sofrem com destruição do meio ambiente e desestruturação do meio de vida devido ao desenvolvimento urbano e aos 
interesses. Além do Ministério do Meio Ambiente, o Ministério Público Federal e o Ministério Público do Estado da Bahia se uniram para encaminhar recomendações a nove bancos (Real, Santander, Unibanco, BNDES, Caixa Econômica Federal, Banco do Brasil, HSBC, Itaú e Bradesco) que financiam obras e atividades de trinta empreendimentos desenvolvidos na capital - a maioria, na Avenida Paralela - com a finalidade de cientificar os bancos sobre o desenvolvimento das obras e a não observação delas à legislação de proteção ambiental.

Entre os impactos e riscos ambientais identificados, verifica-se alteração no ciclo reprodutivo da fauna; alteração no regime tradicional de uso e ocupação do território, assoreamento de recurso hídrico, desmatamento, erosão do solo além de falta e irregularidade na autorização ou licenciamento ambiental. Os riscos envolvem acidentes, doenças transmissiveis, falta de atendimento médico e piora na qualidade de vida.

\section{DISCUSSÃO E CONCLUSÕES}

Ao contrapor os aspectos inadequados ao conceito de sustentabilidade verificados nas três empresas vencedoras do Guia de Sustentabilidade da revista Exame, encontramos 48 danos registrados no Mapa de Conflitos (CONFLITO AMBIENTAL, 2016) que não são mencionadas na revista.

Acredita-se que tal omissão de informação procura não destacar irregularidades diante do público da revista Exame, considerado, assim como o de outras publicações especializadas em negócios, um público representante do retrato da literatura padrão da Administração. Para Ituassu e Tonelli (2014), a cultura management fala de inovações criadas e adotadas rapidamente por um tipo de indústria e hoje forma uma instituição muito difundida. Essas práticas modernas de gestão e organização do trabalho, e a lógica que Ihes é subjacente, ultrapassaram a esfera econômica, que foi sua origem, e se espalharam por diferentes domínios da vida social

Apesar de veículos jornalísticos transmitirem a ideia de uma abordagem neutra e imparcial, a mídia de negócios possui "grande influência sobre as decisões tomadas no mundo corporativo e é considerada como produtora e disseminadora de conhecimento em gestão" (WOOD JR.; PAULA, 2001, p. 12). Esse gênero costuma adotar um perfil de discurso gerencialista e, em geral, tem tanto apelo emocional quanto técnico, combinando os conceitos de autoajuda e management, além de servir como um guia para as decisões relacionadas à carreira na área de negócios (DUARTE; MEDEIROS, 2019).

A revista Exame, ao adotar metodologia e classificação apresentadas como um tipo de conhecimento científico capaz de apoiar as ferramentas de gestão e modelos em discussão desenvolvendo um índice ou "medida" de sustentabilidade reveste-se dessa neutralidade. "Ao mesmo tempo, ao incorporar a técnica 
argumento, transfere o conceito para outro nível, tornando-se legítimo e acrítico" (COSTA; BARROS; MARTINS, 2012, p. 15).

Tanto a mídia jornalística quanto a literatura designada pop-management referem-se a publicações (livros, revistas e jornais de negócios) como artefatos da cultura ou ideologia do management, que efetiva a homogeneização de conceitos e práticas administrativas junto ao público executivo apresentando-se como veículo para a disseminação das ideologias em função de seu poder de comunicação (FONSECA, 2003; COSTA; BARROS; MARTINS, 2012).

Considerando-se que a comunicação de massa se tornou um meio importante de criação, processamento e disseminação de comportamento social, esta mídia serve como um sistema de interpretação da realidade que rege as relações dos indivíduos com seu ambiente físico e social, orientando seu comportamento e prática. Assim, torna-se evidente o poder de influência destes veículos sobre seu público (BARROS; SAUERBRONN; COSTA, 2014). Isso contribui para a homogeneização de práticas e conceitos de gestão, apresentando-se como um importante veículo para a disseminação de ideologias.

Por esse processo, os meios de comunicação enfatizam, selecionam e priorizam certas práticas e discursos, guiando o leitor-gestor na direção considerada interessante pela revista. Vale salientar que ao receber destaque na mídia, a legitimidade das empresas pode ser moldada (e até alterada) pelo grau de visibilidade na mídia (BARROS; SAUERBRONN; COSTA, 2014). Desta forma, estas mídias contribuem para a homogeneização de conceitos e práticas administrativas, apresentando-se como um importante veículo para a disseminação de ideologias na sociedade que depende do âmbito do seu poder de comunicação e sua capacidade para divulgar suas ideias (BARROS; SAUERBRONN; COSTA, 2014).

Quanto às empresas aqui selecionadas, pode-se verificar que as principais vencedoras em termos de visibilidade e colocação possuem uma série de danos registrados pelos Conflitos Ambientais. Os danos não são citados nas matérias da revista. Deste modo, nota-se a omissão de informações importantes que poderiam ser divulgadas em prol de uma avaliação mais crítica da qualidade das condições de trabalho e da sustentabilidade em geral apresentadas pelas empresas, como um comparativo. Acredita-se que o discurso e a premiação não transmitem mensagens neutras, apesar da ideia de uma abordagem jornalística isenta (BARROS; SAUERBRONN; COSTA, 2014). Assim, verifica-se que a linguagem e o discurso reproduzidos pela 'Exame' têm caráter simbólico e ideológico.

Dentro do entendimento mais comum do que vem a ser sustentabilidade, por exemplo, baseando-se na definição de Domeneghetti (2009), defende-se um "conceito" que não deva ser apenas compreendido sob um viés ambiental, mas que envolva, também, dimensões de natureza social e econômica. Em podendo ser a sustentabilidade um slogan e, em sendo um slogan, uma ferramenta que propaga nos meios de comunicação de massa mensagens com pouco rigor, torna-se fato comum que as empresas 
o utilizem de maneira indiscriminada, procurando transmitir uma imagem positiva e alinhada com os valores contemporâneos. Deste modo, o termo acaba sendo tomado como algo cada vez mais valorizado por acionistas e clientes, tornando-se um imperativo para o sucesso das corporações (DOMENEGHETTI, 2009).

Ademais, Lara e Oliveira (2017) relatam que a sustentabilidade no âmbito social é associada à resolução de conflitos e à harmonização com a comunidade local - que muitas vezes é afetada pela atividade empresarial. Para Morais-da-Silva et al. (2018), as organizações que aderem a estratégias que se adequam a sustentabilidade colaboram, em diversas formas, na geração de renda nas comunidades em que atuam. Em consonância, segundo Sena et al. (2017), através dos movimentos sociais esse pilar pode se estabelecer como uma nova forma de atuação do meio social, em que a população possa agir para que seus anseios sejam atendidos.

Como verificado, os feitos apontados como sustentáveis são desenvolvidos em paralelo a outras atividades que podem ser caracterizadas injustas e prejudiciais ao meio ambiente. No entanto, isto não implica dizer que estas empresas são as únicas ou que são vilãs do mercado, mas que, com o destaque, também se torna necessário apontar uma visão que questiona as práticas empresariais por trás das práticas sustentáveis.

Sugere-se para pesquisas futuras realizar a mesma análise com edições mais recentes do Guia de Sustentabilidade da Revista Exame, assim como de outras premiações de sustentabilidade de prestígio, como o Global Climate Action Awards, organizado pelas Nações Unidas e o Prêmio Alemão de Sustentabilidade (Der Deutsche Nachhaltiggkeitspreis).

\section{REFERÊNCIAS}

ALMEIDA, H. J. L. D.; NASCIMENTO JÚNIOR, E. R. D.; COSTA, A. D. J. B. Práticas de sustentabilidade corporativa no Brasil: análise das instituições financeiras integrantes do índice de sustentabilidade empresarial. Gestão e Desenvolvimento, v. 14, n. 1, p. 84-99, 2017.

ABSON, David J. et al. Leverage points for sustainability transformation. Ambio, v. 46, n. 1, p. 30-39, 2017.

BARROS, D. F; SAUERBRONN, F. R.; COSTA, A. M. Corporate sustainability discourses in a Brazilian business magazine. Social Responsibility Journal, v. 10, n. 1, p. 4-20, 2014.

BANERJEE, S. B. Embedding sustainability across the organization: a critical perspective. Academy of Management Learning \& Education. v. 10, n. 4, 2011. 
BANERJEE, S. B. Who Sustains Whose Development? Sustainable development and the reinvention of nature. Organization Studies, 24 (1) p. 143-180, 2003.

BUNGE. Disponivel em: <http://www.bungeacucarebioenergia.com.br/>. Acesso em: 16 maio 2020.

CONFLITO AMBIENTAL. Mapa dos conflitos envolvendo injustiça ambiental e saúde no Brasil. Disponível em: <http://www.conflitoambiental.icict.fiocruz.br/index.php>. Acesso em: jan. 2016.

COSTA, A. M.; BARROS, D. F.; MARTINS, P. E. M. A alavanca que move o mundo: o discurso da mídia de negócios sobre o capitalismo empreendedor. Cadernos EBAPE. BR, v. 10, n. 2, p. 357-375, 2012.

DE LANGE, D. E.; BUSCH, T.; DELGADO-CEBALLOS, J. Sustaining sustainability in organizations. Journal of Business Ethics, v. 110, n. 2, p. 151-156, 2012.

DOMENGHETTI, D. Ativos intangiveis: como sair do deserto competitivo dos mercados e encontrar um oásis de valor e resultados para sua empresa. Rio de Janeiro: Elsevier, 2009.

DUARTE, Maria Paula Ferraz Calfat; MEDEIROS, Cintia Rodrigues de Oliveira. Pop-Management: 15 anos depois-a incorporação do pop-management no trabalho de executivos de grandes empresas. Cadernos EBAPE. BR, v. 17, n. 1, p. 185-198, 2019.

EXAME, Revista. Guia Exame 2015: Sustentabilidade. São Paulo: Abril, 2015.

EXAME. 2016a. Disponível em: <https://www.facebook.com/Exame/?fref=ts>. Acesso em: jan. 2016.

EXAME. 2016b. Exame.com. Disponivel em: <http://exame.abril.com.br/>. Acesso em: jan. 2016.

FIBRIA. O compromisso da empresa com o Futuro. Disponível em: <www.fibria.com.br/web/pt/institucional/sustentabilidade>. Acesso em: jan. 2016.

FREITAS, R. C. M.; NÉLSIS, C. M.; NUNES, L. S. A crítica marxista ao desenvolvimento (in) sustentável. Rev. katálysis, v. 15, n. 1, p. 41-51, 2012.

FONSECA, F. A grande imprensa e a constituição da agenda ultraliberal na nova 'Nova República'. Revista Estudos Históricos, v. 1, n. 31, p. 64-82, 2003.

FOTAKI, M.; PRASAD, A. Questioning neoliberal capitalism and economic inequality in business schools.

Academic of Management Learning \& Education, v. 14, n. 4, p. 556-575. 2015.

GUDYNAS, E. Buen Vivir: Germinando alternativas al desarrollo. América Latina en movimiento, v. 462, p. 1-20, 2011. 
GUDYNAS, E. Estado compensador y nuevos extractivismos: Las ambivalencias del progresismo sudamericano. Nueva sociedad, n. 237, p. 128-146, 2012.

HENRIQUES, M. S.; SANT'ANA, L. F. Ideias-força evidenciadas no discurso organizacional sobre sustentabilidade. Revista Organicom, v. 10, n. 18, 2013.

ITUASSU, Cristiana Trindade; TONELLI, Maria José. Sucesso, mídia de negócios e a cultura do management no Brasil. Cadernos EBAPE. BR, v. 12, n. 1, p. 86, 2014.

JUNG, E. N. "Deslocados Ambientais" e os Desastres. Gestão e Desenvolvimento, v. 14, n. 2, p. 88-98, 2017.

LARA, L. G. A; OLIVEIRA, S. A. A ideologia do crescimento econômico e o discurso empresarial do desenvolvimento sustentável. Cadernos EBAPE. BR, v. 15, n. 2, p. 326-348, 2017.

LOZANO, R. Towards better embedding sustainability into companies' systems: ananalysis of voluntary corporate initiatives. Journal of Cleaner Production, v.25, n.0, p.14-26, 2012.

MARX, K. Crítica da Filosofia de Direito de Hegel. São Paulo: Boitempo, 2005.

MAZLOOMI, M.; HASSAN, A. S. Sustainable Development: Divergences and complexities in Interpretation. In: 2nd INTERNATIONAL CONFERENCE ON BUILT ENVIRONMENT IN DEVELOPING COUNTRIES, $p$. 310-322, 2008.

MEDEIROS, Cintia Rodrigues de Oliveira; SILVEIRA, Rafael Alcadipani da; OLIVEIRA, Luciano Batista de. Mitos no Desengajamento Moral: Retóricas da Samarco em um Crime Corporativo. Revista de Administração Contemporânea, v. 22, n. 1, p. 70-91, 2018.

MESQUITA, R. F. de et al. Divulgação da responsabilidade social e desempenho de universidades brasileiras. Revista Gestão e Desenvolvimento, Novo Hamburgo, v. 17, n. 1, p. 70-86, jan. 2020.

MESQUITA, R. F.; MATOS, F. R. N. A abordagem qualitativa nas ciências administrativas: aspectos históricos, tipologias e perspectivas futuras. Revista Brasileira de Administração Científica, v. 5, n. 1, p. 7-22, 2014.

MILNE, M. J.; KEARINS, K.; WALTON, S. Creating adventures in wonderland: The journey metaphor and environmental sustainability. Organization, v. 13, n. 6, p. 801-839, 2006.

MISOCZKY, M. C.; AMANTINO-DE-ANDRADE, J. Uma crítica à crítica domesticada nos estudos organizacionais. Revista de Administração Contemporânea, v. 9, n. 1, p. 193-210, 2005. 
MORAIS-DA-SILVA, R. L. et al. Empresas atuantes na base da pirâmide e suas contribuições para a sustentabilidade: quadro de análise e evidências empíricas. Cadernos EBAPE. BR, v. 16, n. 2, p. 286-301, 2018.

MORI, K.; CHRISTODOULOU, A. Review of sustainability indices and indicators: Towards a new City Sustainability Index (CSI). Environmental Impact Assessment Review, v. 32, n. 1, p. 94-106, 2012.

MOURA, Guilherme Lima. Hipergeneralizações: organizações são quase qualquer coisa em best-sellers de introdução à Administração. Cadernos EBAPE. BR, v. 12, n. 1, p. 62-85, 2014.

REDCLIFT, M. The environment and carbon dependence landscapes of sustainability and materiality. Current Sociology, v. 57, n. 3, p. 369-387, 2009.

ROBINSON, J. Squaring the circle? Some thoughts on the idea of sustainable development. Ecological economics, v. 48, n. 4, p. 369-384, 2004.

SENA, A. M. C. et al. Abordagem grassroots e resistência: atualizando a concepção de desenvolvimento sustentável. Cadernos EBAPE. BR, v. 15, n. 3, p. 651-666, 2017.

SLIMANE, M. Role and relationship between leadership and sustainable development to release social, human, and cultural dimension. Social and Behavioral Sciences, v. 41, p. 92-99, 2012.

SHRIVASTAVA, Paul; BERGER, Stephanie. Sustainability principles: A review and directions. Organization Management Journal, v. 7, n. 4, p. 246-261, 2010.

SHRIVASTAVA, P. Environmental technologies and competitive advantage. Strategic Management Journal, v. 16, n. S1, p. 183-200, 1995.

SHRIVASTAVA, P. Castrated environment: Greening organizational studies. Organization Studies, v. 15, n. 5, p. 705-726, 1994.

SICA, L. P. P.; BIANQUINI, H.; TERRERI, A. As companhias brasileiras são socialmente sustentáveis? Uma análise das iniciativas de sustentabilidade social das companhias. 2019.

SILVA, J. P. S. Impactos ambientais causados por mineração. Revista Espaço da Sophia, 8, 2007.

VEIGA, J. E. Sustentabilidade - A legitimação de um novo valor. São Paulo: Senac, 2010.

VERDUM, R. Os riscos do neo-extrativismo progressista. Orçamento \& Política Ambiental, n. 23, 2009. WOOD JR, Thomaz; DE PAULA, Ana Paula. Pop-management. Anais do XXV Encontro Nacional de Pós-Graduação em Administração, Campinas, Brasil, 2001. 